\title{
Short-term transplantation of isolated human ovarian follicles and cortical tissue into nude mice
}

\author{
Marie-Madeleine Dolmans, Belen Martinez-Madrid, Elodie Gadisseux, Yves Guiot ${ }^{1}$, Wu Yuan \\ Yuan, Antoine Torre, Alessandra Camboni, Anne Van Langendonckt and Jacques Donnez \\ Gynecology Research Unit and ${ }^{1}$ Pathology Department, Université Catholique de Louvain, 1200 Brussels, Belgium \\ Correspondence should be addressed to J Donnez; Email: donnez@gyne.ucl.ac.be
}

\begin{abstract}
This study was designed to evaluate follicular survival and growth after short-term transplantation of fresh isolated human follicles and ovarian cortical tissue to nude mice. Ovarian biopsies were obtained from nine women undergoing laparoscopy. Twelve nude mice were xenografted with an ovarian cortical fragment in the right ovarian bursa, and a clot containing isolated follicles in the left, for a period of 7 days. One ungrafted fragment was used as a control. Histological sections were analyzed to determine follicle number and stage. The proliferative status of follicular cells was assessed by Ki-67 immunostaining. A total of 659 follicles was analyzed by histology and 545 follicles by immunohistochemistry. The percentage of primordial follicles was found to be markedly reduced 1 week post-grafting when compared with ungrafted tissue, while the percentage of primary follicles had significantly increased. Only $8 \%$ of follicles showed Ki-67-positive granulosa cells before grafting, whereas 1 week after grafting, $71 \%$ of follicles in fragments and $67 \%$ of isolated follicles were Ki-67-positive $(\boldsymbol{P}<\mathbf{0 . 0 0 1})$. Moreover, the histological aspect of isolated follicle grafts was similar to that of grafted fragments: follicles were surrounded by vimentin-positive stroma-like tissue of human origin, as confirmed by fluorescent in situ hybridization with human-specific probes. Our results demonstrate, for the first time, that isolated human follicles are able to survive and grow after xenografting. This study also shows massive in vivo follicular activation after transplantation of grafted fragments and isolated follicles. One week after grafting, well-structured stroma-like tissue of human origin was observed around the isolated follicles. The potential origin of this stroma is discussed.

Reproduction (2007) 134 253-262
\end{abstract}

\section{Introduction}

Cryopreservation of ovarian tissue is presently the only available option to sustain fertility in prepubertal girls and women at risk of premature ovarian failure, who cannot delay the start of chemotherapy. It has already been proved that autologous transplantation of cryopreserved ovarian cortical strips can restore fertility in humans, yielding two live births (Donnez et al. 2004, Meirow et al. 2005) and one clinical pregnancy (Demeestere et al. 2006) to date.

However, issues such as safeguarding patients from cancer cell reintroduction and minimizing ischemic tissue damage require further investigation, as they are critical to the safety and efficacy of clinical ovarian tissue preservation and grafting (Donnez et al. 2006). This led us to consider an alternative strategy, which involves grafting isolated ovarian follicles. In humans, collagenase digestion is currently used to isolate preantral follicles (Oktay et al. 1997, Hovatta et al. 1999, Abir et al. 2001, Huntriss et al. 2002, Martinez-Madrid et al. 2004, Schröder et al. 2004), but isolating human follicles is particularly challenging because of the fibrous and dense nature of the human ovarian stroma. Studies have revealed alterations in the basal lamina of follicles after collagenase digestion (Eppig 1994) and Hovatta et al. (1999) reported more markedly premature oocyte extrusions from follicles that had been partially isolated using collagenase. An optimized protocol with Liberase digestion was therefore developed (Dolmans et al. 2006), yielding good quality isolated human follicles, which is an absolute prerequisite for the further successful processing of these follicles, either for culture or for transplantation.

In mice, a study by Gosden (1990) demonstrated that ovarian tissue can be enzymatically digested before being grafted to the ovarian bursa of sterile mice, whereby the ovarian digest is reorganized into morphologically distinguishable ovaries. The ability of dispersed ovarian cells (stroma and follicles) to reorganize into a 
functioning organ allows restoration of fertility after transplantation (Carroll \& Gosden 1993).

The objective of our study was to evaluate the viability and growth of enzymatically isolated human follicles after xenotransplantation. For this purpose, ovarian tissue was digested with Liberase, and the isolated follicles were picked up and embedded in a clot for grafting to the ovarian bursa of nude mice for 7 days. For comparison, a cortical fragment was grafted to the contralateral bursa of the same mouse.

\section{Materials and Methods}

\section{Experimental design}

In order to assess and compare follicular survival and growth after short-term grafting of fragments and isolated follicles, human ovarian biopsies were divided into three experimental subgroups: (1) ungrafted ovarian tissue, fixed immediately after biopsy; (2) grafted fragments, transplanted for 7 days to the right ovarian bursa of nude mice; and (3) grafted isolated follicles transplanted to the left ovarian bursa of the same mice after embedding in a plasma clot, as described below.

The following analyses were conducted in the three groups: (1) classic histology of follicular stages, (2) immunostaining with anti-inhibin- $\alpha$ to clearly identify follicles in the grafts, (3) immunostaining with anti-Ki-67 antibodies to assess proliferative activity in the grafted follicles, and (4) fluorescent in situ hybridization (FISH) using a probe specific for the human $X / Y$ chromosomes, and immunolabeling with anti-human vimentin-specific staining (a marker of stromal cells) to confirm the human origin of the graft.

\section{Collection and dissection of ovarian tissue}

The use of human tissue for this study was approved by the Institutional Review Board of the Université Catholique de Louvain. Ovarian biopsies were taken from nine women (between 23 and 32 years of age, mean 27.1 years) after obtaining written informed consent. They were all undergoing laparoscopic surgery for benign gynecologic disease. Only seven biopsies yielding a high number of follicles were grafted. Indeed, two biopsies were excluded from the study as too few isolated follicles (17 and 3 respectively) were recovered.

Tissue was immediately transported from the operating room to the research laboratory in HEPES-buffered Modified Eagle Medium (HEPES-MEM; Gibco) on ice. The medullar part was removed from the ovarian biopsies using surgical scissors and the cortical tissue was distributed among the three groups. In group 1 (ungrafted tissue), a $\pm 1 \mathrm{~mm}^{3}$ piece was immediately fixed in $4 \%$ formaldehyde and served as a control. In group 2 (grafted fragments), one piece of $1 \mathrm{~mm}^{3}$ was placed in HEPES-MEM at $4{ }^{\circ} \mathrm{C}$ until transplantation.
In group 3 (grafted isolated follicles), the remainder of the biopsy $( \pm 3 \times 4 \times 1 \mathrm{~mm})$ was treated to release the follicles, as described below.

\section{Isolation of follicles}

Follicles were isolated according to the procedure described by Dolmans et al. (2006). Briefly, ovarian cortical tissue to be processed was placed in a tissue sectioner (Mcllwain Tissue Chopper, Mickle Laboratory, Guildford, UK), adjusted to $0.5 \mathrm{~mm}$. The cutting procedure was swift $(<5 \mathrm{~min})$, and uniform-size pieces of $0.5 \times 0.5 \times 1 \mathrm{~mm}$ were obtained.

Fragments were transferred to $50 \mathrm{ml}$ conical tubes (Greiner Bio-one, Brussels, Belgium) containing $10 \mathrm{ml}$ Dulbecco's PBS (Biochrom AG, Berlin, Germany) supplemented with $0.04 \mathrm{mg} / \mathrm{ml}$ Liberase blendzyme 3 (Roche). Incubation was performed in a water bath at $37^{\circ} \mathrm{C}$ with gentle agitation for $75 \mathrm{~min}$. Every $15 \mathrm{~min}$, the cell suspension was aspirated up and down with a $10 \mathrm{ml}$ pipette (Cellstar, Greiner, Frickenhaussen, Germany) to mechanically disrupt digested tissue. Digestion was terminated by the addition of an equal volume of cold PBS supplemented with $10 \%$ fetal bovine serum (FBS; Sigma).

The resulting suspensions were then centrifuged at $50 \mathrm{~g}$ for $10 \mathrm{~min}$ at $4{ }^{\circ} \mathrm{C}$. The pellets were resuspended in PBS supplemented with $10 \%$ FBS, transferred to Petri dishes, and investigated for follicles under a stereomicroscope (Leica, Van Hopplynus Instruments, Brussels, Belgium). The follicles were picked up using a $130 \mu \mathrm{m}$ micropipette (Flexipet, COOK, Ireland) and washed three times in PBS supplemented with $10 \%$ FBS (Fig. $1 \mathrm{~A}$ and $\mathrm{B}$ ).

\section{Transplantation into nude mice}

After isolation and collection, follicles were embedded in plasma clots, serving as vehicles to facilitate subsequent grafting, as described by Gosden (1990) (Fig. 1C). To obtain a clot, the patient's blood was centrifuged at $405 \mathrm{~g}$ for $15 \mathrm{~min}$ at $4{ }^{\circ} \mathrm{C}$ and the supernatant was recovered. Fresh human autologous venous plasma $(20 \mu \mathrm{l})$ was then injected with an average of 88 isolated follicles (range 41-177) using a micropipette under visual control. Clotting was induced by adding a drop of $1 \mathrm{M} \mathrm{CaCl}_{2}$ (1:40 dilution), followed by incubation at $37^{\circ} \mathrm{C}$ for $30 \mathrm{~min}$. The clot then acquired a jelly-like consistency and it was possible to pick it up with surgical forceps to transplant it into the mouse ovarian bursa. The procedure for plasma clot preparation and grafting is illustrated in Fig. 1.

The follicular population was not characterized before grafting. Evaluation of follicular size can only be done under a microscope, which would considerably prolong the time to grafting, altering follicle viability. In our 
A

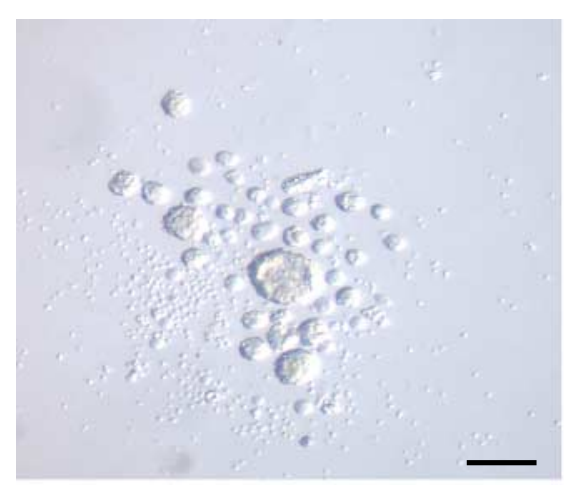

C

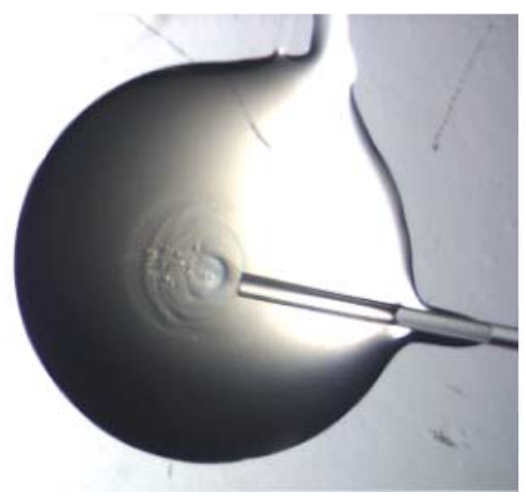

B

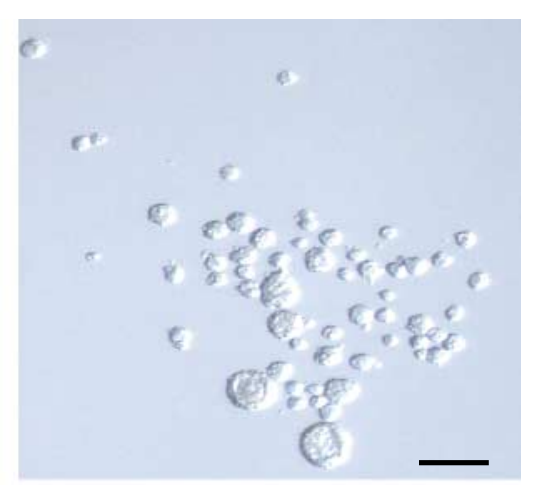

D

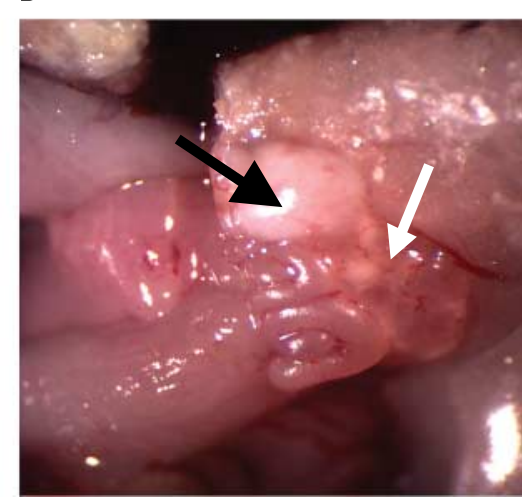

Figure 1 Preparation and grafting of the plasma clot containing isolated follicles. (A and B) Enzymatically isolated human follicles seen under a stereomicroscope. Scale bar $=100 \mu \mathrm{m}$. Isolated follicles just after follicle pick-up (A) and after the rinsing procedure (B). (C) Constitution of the clot: follicles are injected into the clot with a micropipette. (D) Macroscopic view of the left ovarian bursa grafted with isolated follicles embedded in a clot on the day of transplantation. Black arrow: grafted clot. White arrow: mouse ovary. previous experiments, the proportion of primordial and growing follicles was evaluated after isolation. The proportion of primordial follicles recovered after isolation ranged between 60 and $70 \%$ of total follicles (data not shown).

Twelve nude (Swiss nu/nu) 6- to 10-week-old female mice (Charles River B Laboratories, Brussels, Belgium) were operated on. The mice were bred as described previously (Nisolle et al. 2000).

Cortical fragments awaiting transplantation were placed in fresh HEPES-MEM and prepared for grafting. The average delay between biopsy collection and grafting was $5 \mathrm{~h}$.

I.p. injection of ketamine $(75 \mathrm{mg} / \mathrm{kg}$; Anesketin, Eurovet, Heusden-Zolder, Belgium) and medetomidine $(1 \mathrm{mg} / \mathrm{kg}$; Domitor, Pfizer, Cambridge, MA, USA) was administered for anesthesia, and buprenorphine $(0.1 \mathrm{mg} / \mathrm{kg}$, Temgesic, Schering Plough, Kenilworth, NJ, USA) for analgesia. A lateral incision of $0.5 \mathrm{~cm}$ was performed bilaterally. A small slit was made in the ovarian bursal membrane to place an ovarian cortical fragment into the right ovarian bursa and a clot containing isolated follicles into the left ovarian bursa. The abdominal wall and skin were closed with $7 / 0$ Prolene. After surgery, anesthesia was reversed by injection of atipamezole ( $1 \mathrm{mg} / \mathrm{kg}$; Antisedan, Pfizer). The animals were euthanized after 7 days by cervical dislocation, and all the murine ovarian bursae were recovered and fixed in formaldehyde.

\section{Histological evaluation}

For all three groups (ungrafted tissue, grafted fragments and grafted clots), tissue was fixed in $4 \%$ formaldehyde, embedded in paraffin and serially sectioned ( $5 \mu \mathrm{m}$-thick sections). Every third slide was stained with hematoxylin-eosin (Merck) for histological evaluation; the others (Superfrost Plus slides, Menzel-Glaser, Braunschweig, Gemany) were kept for immunostainings and FISH (Figs 2 and 4).

The follicles were counted and classified according to stage into primordial, intermediate, primary, or secondary (Lass et al. 1997). Primordial follicles had one layer of flattened granulosa cells, intermediate follicles had both flattened and cuboidal granulosa cells, primary follicles had one layer of cuboidal granulosa cells and secondary follicles had two or more layers of cuboidal granulosa cells (Gougeon 1996). Two independent observers (M M D and E G) blindly analyzed 12 sections per mouse after hematoxylin-eosin staining, and a further 12 sections per mouse after Ki-67 immunostaining. The analyzed sections were taken at $50 \mu \mathrm{m}$ intervals, ensuring that no preantral follicle was counted twice (Lass et al. 1997).

\section{Immunohistochemistry}

Follicular proliferation was measured by evaluating the percentage of follicles with Ki-67-positive granulosa cells (Fig. 2B). Ki-67 is a nuclear antigen associated with 


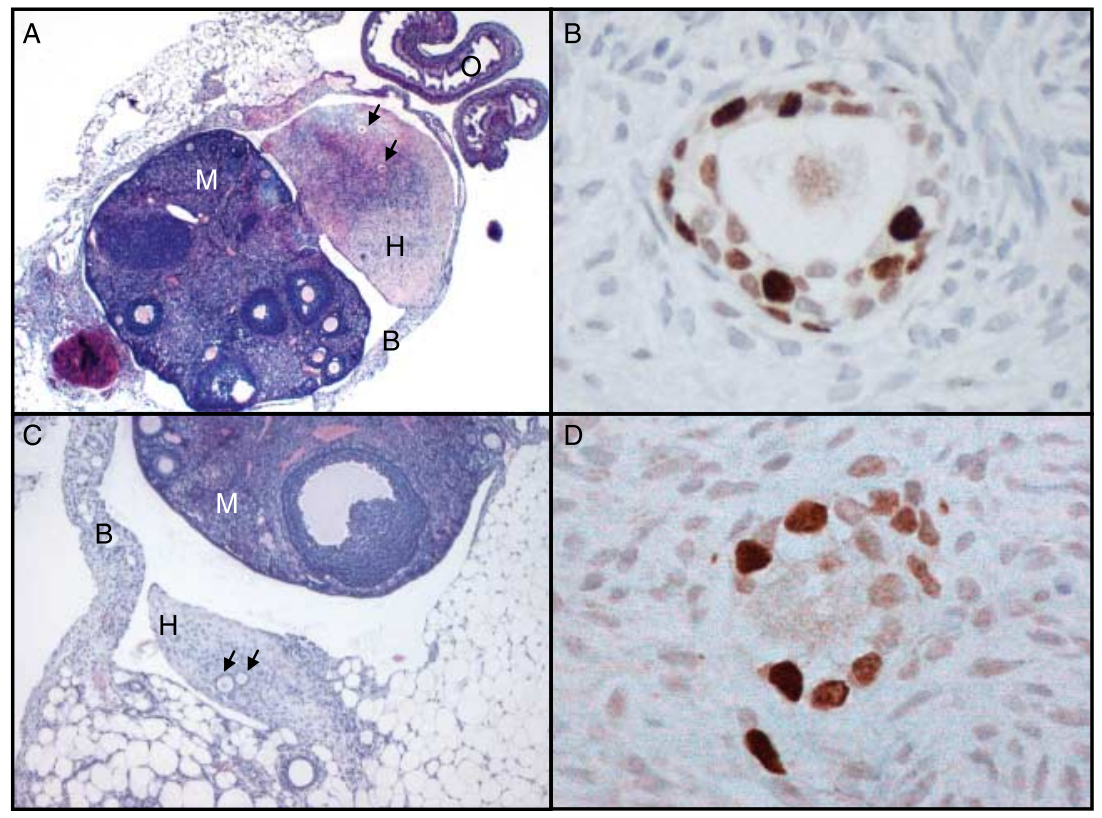

Figure 2 (A) Histological section of a human cortical fragment grafted into the murine ovarian bursa for 7 days. $\mathrm{H}$, human ovarian fragment; $\mathrm{M}$, mouse ovary; $\mathrm{O}$, mouse oviduct; $\mathrm{B}$, mouse ovarian bursa. Two follicles are shown by an arrow. Original magnification $\times 25$. (B) Immunohistochemical staining for $\mathrm{Ki}-67$ in a secondary follicle embedded in a grafted fragment. Original magnification $\times 400$. (C) Histological section of a clot containing human isolated follicles 7 days after transplantation. $\mathrm{H}$, human graft; $\mathrm{M}$, mouse ovary; B, mouse ovarian bursa. Two follicles are shown by an arrow. Original magnification $\times 50$. (D) Immunohistochemical staining for $\mathrm{Ki}-67$ in a primary follicle embedded in a grafted clot. Original magnification $\times 400$. cell proliferation and is present throughout the active cell cycle (late G1, S, G2, and M phases) but absent in resting cells (G0). Results were analyzed according to the follicular stage in the three different groups.

In order to facilitate identification of follicles, immunohistochemical analysis of inhibin- $\alpha$ was performed. Inhibin has two isoforms, A and B, with the same $\alpha$-subunit but different $\beta$-subunits. Inhibin- $\alpha$ subunit is detected in granulosa cells at all follicular stages (Bristol \& Woodruff 2004).

To assess the species specificity of grafted cells, immunostaining was carried out with anti-human vimentin-specific antibodies (Fig. 4A-C). Vimentin is a cytoskeletal protein considered to be a marker of cells of mesenchymal origin. It is strongly expressed in ovarian stromal and granulosa cells from growing follicles (Czernobilsky et al. 1985).

Embedded sections were deparaffinized with Histosafe (Yvsolab SA, Beerse, Belgium) and rehydrated in 2-propanol (Merck). Endogenous peroxidase activity was blocked by incubating the sections with $0.3 \% \mathrm{H}_{2} \mathrm{O}_{2}$ (Merck) for $30 \mathrm{~min}$ at room temperature. The sections were decloaked in citrate buffer for $75 \mathrm{~min}$ at $98{ }^{\circ} \mathrm{C}$ before incubation with goat serum to block non-specific binding sites for $30 \mathrm{~min}$. The sections were incubated overnight with primary antibodies: rabbit anti-human Ki-67 IgG $\left(4{ }^{\circ} \mathrm{C}, 1: 250\right.$ dilution; A0047, Dako, Glostrup, Denmark), mouse monoclonal anti-human inhibin- $\alpha$ IgG (room temperature, 1:10 dilution; MCA 951S, Serotec, Oxford, UK) or mouse monoclonal antihuman vimentin IgG1 (room temperature, 1:50 dilution; Clone V9, Novocastra, Newcastle, UK). The slides were subsequently incubated for $60 \mathrm{~min}$ at room temperature with secondary antibodies: goat anti-rabbit (Dako, K4003) or goat anti-mouse (1:2 dilution, Dako,
K4000). Diaminobenzidine (Dako) was used as a chromogen and nuclei were counterstained with hematoxylin.

Human proliferative endometrium was used as a positive control for Ki-67 labeling and human placental tissue for inhibin- $\alpha$ staining. To check the specificity of anti-human vimentin immunostaining, human ovarian tissue was included as a positive control and mouse ovarian tissue as a negative control.

\section{Fluorescent in situ hybridization}

Grafted clot sections were assayed for the presence of human cells using FISH with human-specific genomic probes (Fig. 4D-F). For this purpose, a protocol was set up to perform FISH on formaldehyde-fixed, paraffinembedded ovarian tissue. Grafted fragments were used as positive controls and mouse ovarian tissue as negative controls to test FISH specificity.

Briefly, $5 \mu \mathrm{m}$ paraffin sections were deparaffinized, dehydrated (in ethanol), air-dried, and pretreated with $0.2 \mathrm{M} \mathrm{HCl}(20 \mathrm{~min})$, followed by $1 \mathrm{M} \mathrm{NaSCN}$ in $2 \times \mathrm{SSC}$ at $80{ }^{\circ} \mathrm{C}$ (30 min). After washing $(2 \times \mathrm{SSC})$, the sections were digested by $0.25 \mathrm{mg} / \mathrm{ml}$ proteinase K (Sigma) for $3 \mathrm{~min}$ at $45^{\circ} \mathrm{C}$ and directly post-fixed for $10 \mathrm{~min}$ in $4 \%$ paraformaldehyde. Denaturation of DNA was performed by soaking slides in $70 \%$ formamide in $2 \times \mathrm{SSC}$ at $72{ }^{\circ} \mathrm{C}$ for 5 min, dehydrating, and air-drying them. A cocktail of CEP $X / Y$ DNA probes was used following the manufacturer's recommendations (Vysis, Downers Grave, IL, USA). After overnight incubation (at $37^{\circ} \mathrm{C}$ ), the slides were washed in $2 \times \mathrm{SSC}$ containing $0.3 \% \mathrm{NP} 40$ at $45^{\circ} \mathrm{C}(5 \mathrm{~min})$ and at $73{ }^{\circ} \mathrm{C}$ (2 min). Finally, they were air-dried and mounted with Vectashield (Vector Laboratories) containing 4',6diamidino-2-phenylindole (DAPI). 
Hybridization signals were observed with a fluorescent Axioskop 40 microscope (Zeiss, Oberkochen, Germany), equipped with an Infinity-x camera (Deltapix, Lumenera Corporation, Ottawa, Ontario, Canada). Two pictures of the same field were taken using two different filters, one for DAPI (blue) and one for the green spectrum to detect nuclei and human $\mathrm{X}$ chromosomes respectively.

Merged images allowed us to identify co-localization.

\section{Statistical analysis}

Analyses were performed using the SPSS (Chicago, IL, USA) 11.5 program. One-way ANOVA was conducted to validate the double-blind procedure. Follicle classification results (primordial, intermediate, primary, and secondary) were compared between the three groups (ungrafted tissue, grafted fragments, and grafted clots). A comparison of the follicular proliferation rate was also made between the three groups and for each follicular stage. Differences between the study groups were calculated and general linear model statistical analysis was applied to the results, followed by a Bonferroni post hoc test. Values of at least $P<0.05$ were considered statistically significant.

\section{Results}

\section{Histological evaluation}

The right and left ovarian bursae (containing both ovary and graft) were removed from the 12 mice, 7 days after grafting. Ovarian fragments and clots containing isolated follicles were identified after histological examination of the ovarian bursae and follicular inhibin- $\alpha$ immunostaining. The recovery rate was $75 \%(9 / 12)$ for grafted fragments and $58.3 \%(7 / 12)$ for grafted clots. This can be explained by the extrusion of some grafts out of the bursa. Indeed, at histology, some clots were detected just outside the ovarian bursa.

Ovarian follicles were identified in $100 \%$ of recovered xenografts. Serial histological sections were analyzed to determine follicle number and stage. The mean number of follicles recovered from grafts was $36.5 \pm 27$ per grafted fragment (9 fragments yielding 329 follicles in total). The mean number of recovered follicles was $17.9 \pm 10.4$ ( \pm S.E.M.) per grafted clot. For isolated follicles, as it was known exactly how many were grafted, a recovery rate of $20.3 \%$ could be precisely calculated.

The follicles were classified according to developmental stage, as detailed in Fig. 3. In the hematoxylineosin-stained sections, a total of 388, 216, and 55 follicles were analyzed in ungrafted tissue, grafted fragments, and grafted clots respectively. A comparison between the three groups (Fig. 3) revealed that there was a significant decrease in the proportion of primordial follicles in grafted tissue when compared with ungrafted tissue. Indeed, the percentage of primordial follicles

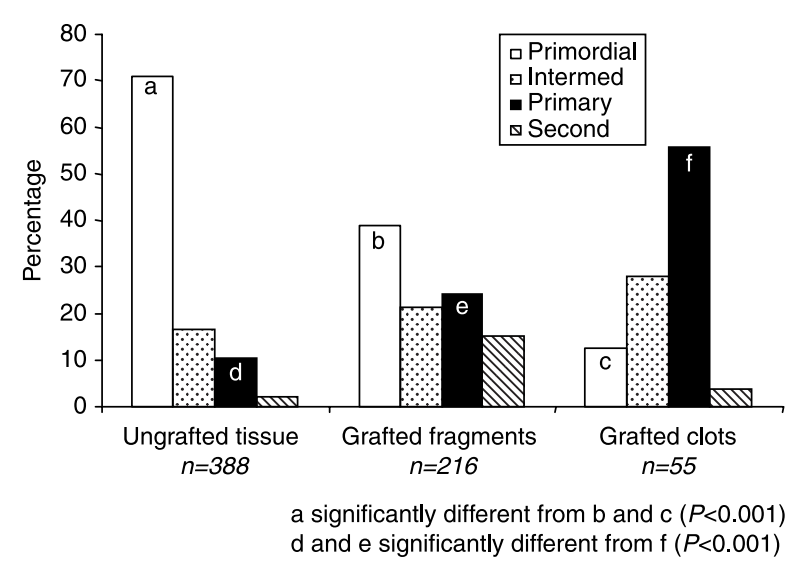

Figure 3 Histological evaluation and follicular classification (primordial, intermediate, primary, or secondary) in ungrafted tissue, grafted fragments, and grafted isolated follicles.

present in ungrafted tissue $(71 \%)$ was significantly diminished 1 week post-grafting (39 and 13\% in grafted fragments and grafted clots respectively).

On the other hand, the percentage of intermediate follicles increased from $16.6 \%$ in ungrafted tissue to 21.4 and $27.9 \%$ in grafted fragments and grafted clots respectively. This increase in intermediate follicles was not statistically significant. However, there was a significant increase in the percentage of primary follicles, from $11 \%$ in ungrafted tissue to $24 \%$ in grafted fragments and $56 \%$ in grafted clots $(P=0.05$ and $<.001$ respectively).

Secondary follicles were scarce (respectively 9, 29, and 2 in ungrafted tissue, grafted fragments, and grafted clots) and, therefore, no statistical analysis was conducted.

Histological study also demonstrated the presence of stroma-like cells in isolated follicle grafts (Fig. 2A), which showed a similar architecture to human ovarian cortical tissue (Fig. 2C).

\section{Characterization of stroma-like tissue in isolated follicle grafts}

\section{Vimentin staining}

In order to assess whether the identified stroma-like cells were of human or murine origin, grafted clots were immunolabeled with anti-human vimentin antibodies. As illustrated in Fig. 4A and B, vimentin immunostaining was specific for human tissue; staining was strong in ungrafted human ovarian tissue (Fig. 4B) but not detectable in mouse ovarian tissue (Fig. 4A). In control ungrafted human tissue, vimentin immunoreactivity was detected in the cytoplasm of human stromal cells.

In isolated follicle grafts, the stroma-like tissue stained positive for human vimentin, confirming the cells were of human origin (Fig. 4C), while no immunoreactivity 
A

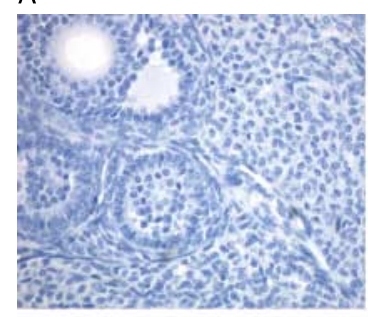

$\mathrm{D}$

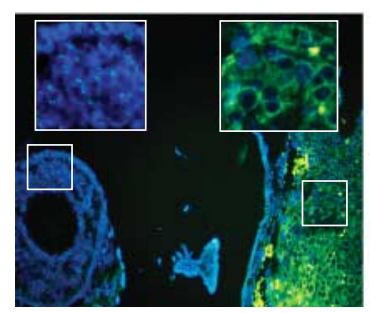

B

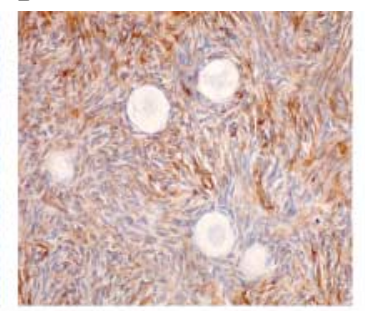

E

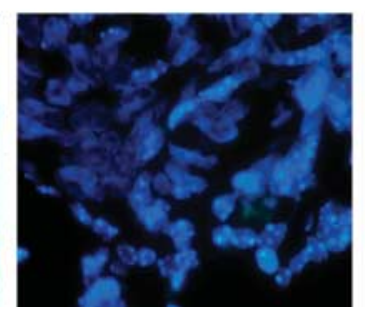

C

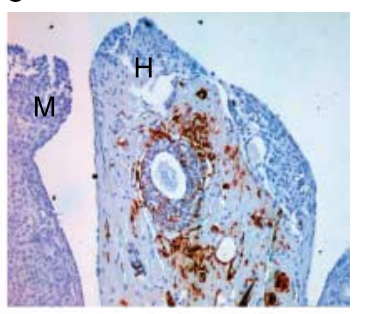

F

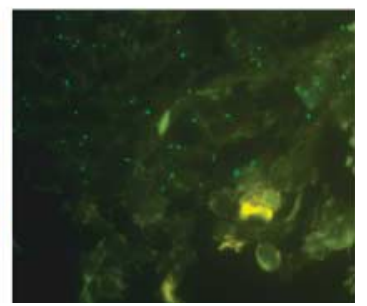

Figure 4 Origin of the stroma-like tissue in grafted clots: anti-human vimentin immunostaining (A-C) and FISH characterization (D-F). (A) No staining with the specific anti-human vimentin antibody on mouse ovarian stromal tissue (original magnification $100 \times$ ). (B) Anti-human vimentin immunostaining on ungrafted human ovarian tissue: positive staining of human ovarian stromal cells (original magnification $100 \times$ ). (C) Anti-human vimentin immunostaining on xenografted human follicles in mice: positive cells can be seen in the stroma-like tissue of grafted human follicles $(\mathrm{H})$, while mouse ovarian stroma (M) remains negative (original magnification 200X). (D) Control slide (original magnification $40 \times$ ): FISH using a probe specific for human X chromosome on xenografted human ovarian fragments in mice. This is a merged image obtained after DAPI staining (blue nuclear staining) and FISH staining (green double spots). Double spots, staining the 2 human X chromosomes of human cells, are visible in human cells only (left magnification: positive human granulosa cells). No double spots are visible in mouse tissue. The green halo around the mouse cells (right magnification) indicates that the proteinase $\mathrm{K}$ enzymatic digestion of mouse ovarian tissue is less effective than its human counterpart. (E and $\mathrm{F}$ ) FISH characterization of the stroma-like tissue in grafted clots (original magnification $\times 100$ ). (E) DAPI staining of the stroma in grafted clots. (F) FISH anti-human X chromosomes showing positive stromal cells with double spots in grafted clots.

was detected in mouse ovaries, confirming the human specificity of the immunostaining.

\section{FISH}

The presence of human cells in the stroma-like tissue of grafted clots was confirmed using FISH with humanspecific genomic probes. The species specificity of the probes was checked on human ovarian tissue grafted to the murine ovarian bursa. As illustrated in Fig. 4D, the probes only hybridized to human ovarian cells, but not to their mouse counterparts.

Hybridization of stroma-like tissue from isolated follicle clots with human-specific DNA probes showed numerous positive cells (Fig. 4F), confirming the presence of human cells in the restructured tissue 7 days after isolated follicle grafting.

\section{Ki-67 immunohistochemistry of follicular cells}

Follicular proliferation was measured by evaluating the percentage of Ki-67-positive follicles. Follicles with at least one $\mathrm{Ki}-67$-stained granulosa cell were considered to have initiated growth (Gougeon \& Busso 2000, Oktay et al. 2000). Figure 5A presents the total (including all follicular stages) follicular proliferation rate of each group. In Ki-67-stained sections, 545 follicles were analyzed: 289 in ungrafted tissue, 176 in grafted fragments and 80 in grafted clots. In ungrafted tissue, only $8 \%$ of follicles showed Ki-67-positive granulosa cells, whereas $71 \%$ of follicles in grafted fragments and $67 \%$ of grafted isolated follicles were Ki-67-positive $(P<0.001) 1$ week after grafting.

Figure $5 \mathrm{~B}$ shows the follicular proliferation rate of each follicular stage in the three groups. For each stage (primordial, intermediate, primary, and secondary), there was an increase in the proportion of Ki-67-positive follicles 1 week after grafting.

The percentage of Ki-67-positive primordial follicles was very low in ungrafted tissue $(0.7 \%)$. However, this percentage significantly increased 1 week post-transplantation in both grafted fragments $(10.1 \%)$ and grafted isolated follicles $(15 \% ; \quad P=0.05$ and $P=0.039$ respectively).

With regard to intermediate follicles, $17.9 \%$ were $\mathrm{Ki}$ 67-positive in ungrafted tissue, but this figure rose to 83.3 and $62.5 \%$ in grafted fragments and grafted clots respectively 1 week after transplantation $(P \leq 0.001)$. While $40.7 \%$ of primary follicles were Ki-67-positive in ungrafted tissue, this percentage climbed to 95.1 and $87.7 \%$ in grafted fragments and grafted clots respectively $(P \leq 0.001)$.

In all three groups, almost all the secondary follicles were Ki-67-positive and the slight increase observed 
A

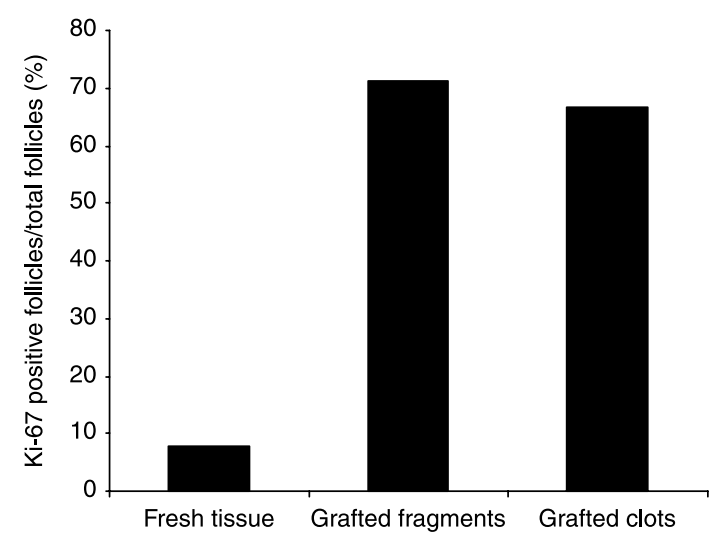

B

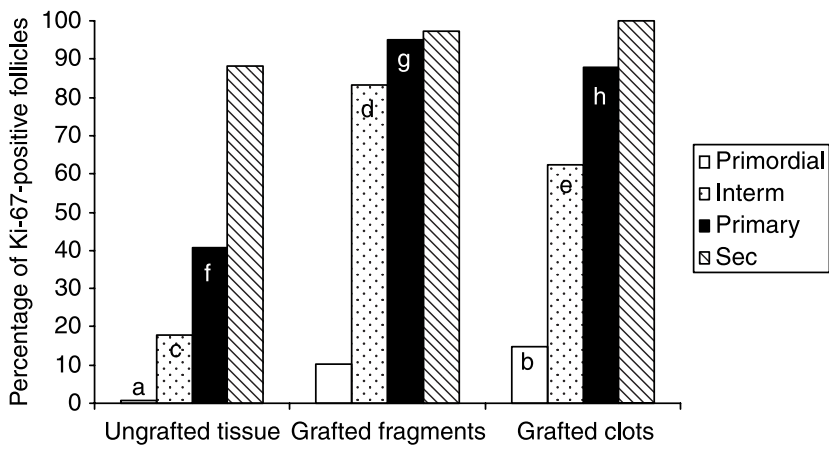

a Significantly different from $\mathrm{b}(P<0.05)$

c Significantly different from $\mathrm{d}$ and e $(P<0.001)$

$\mathrm{f}$ Significantly different from $\mathrm{g}$ and $\mathrm{h}(P<0.001)$

Figure 5 (A) Total (including all follicular stages) follicular proliferation rate measured by evaluating the percentage of $\mathrm{Ki}$-67-positive follicles in ungrafted tissue, grafted fragments, and grafted isolated follicles.

(B) Follicular proliferation rate for each follicular stage in the three groups.

after grafting (from $88 \%$ to 97 and 100\%) was not significant.

When comparing grafted fragments and grafted isolated follicles, there was no significant difference in the proportion of Ki-67-positive follicles between these two groups.

\section{Discussion}

The objective of the present study was to evaluate the viability and growth capacity of enzymatically isolated human follicles 7 days after xenotransplantation.

Our previous studies demonstrated that follicles recovered after digestion of human ovarian cortex using the Liberase enzyme blend have a well-preserved ultrastructure and are viable, as assessed by fluorescent staining (Dolmans et al. 2006). After enzymatic (Liberase) isolation, fluorescent staining (calcein-AM and ethidium homodimer-I) proved that almost $86 \%$ of isolated follicles contained viable oocytes and granulosa cells. Moreover, a proportion of these enzymatically isolated follicles retained the capacity to grow in vivo.

Their survival and growth is evidenced by their morphologically normal structure, their progression to more advanced follicular stages, and their positive staining for Ki-67 1 week post-transplantation. Furthermore, our preliminary data indicate that isolated follicles grafted for 6 months can reach tertiary and antral stages, demonstrating the capacity of the oocyte to survive and grow further (data not shown). However, the fact that the oocyte is viable does not necessarily mean that it is functionally normal. To our knowledge, this is the first study to show that isolated human primordial follicles are able to survive and grow in vivo after xenografting.

The most intriguing observation in this study was the presence of stroma-like cells of human origin in isolated follicle grafts (Fig. 2C), although only follicles isolated from their surrounding stroma were grafted. This stromalike tissue may arise either from contaminating stromal cells grafted together with the isolated follicles, or from the differentiation of granulosa cells into a stromal cell type. The former hypothesis is the most likely. In studies by Carroll \& Gosden (1993), dispersed ovarian cells were able to reorganize into a functioning organ in vivo, which led to the restoration of fertility in mice. However, in the present study, isolated follicles were separated from stromal cells after digestion of the ovarian cortex. This was performed by picking up the follicles with a pipette and washing them three times in fresh medium to remove remaining stromal cells. These follicles were then embedded in a plasma clot as a vehicle for transfer. One cannot therefore entirely exclude the presence of a few stromal cells in the plasma clot.

The latter hypothesis on the differentiation of granulosa cells cannot be ruled out either, however, as a study by Antczak \& Van Blerkom (2000) revealed that granulosa cells from mature oocytes retain the ability to differentiate into other cell types (vascular endothelial cells) in vitro.

As demonstrated previously by Baird et al. (2004) after grafting of sheep cortical tissue, follicular activation was observed during the first days post-grafting. In the present study, this activation phenomenon occurred in both transplantation groups (cortical fragments and isolated follicles). This was evidenced by a significant reduction in the proportion of primordial follicles, but concomitant increase in the proportion of intermediate and primary follicles 1 week after grafting, accompanied by a much higher percentage of follicles with Ki-67-positive granulosa cells. Indeed, granulosa cell proliferation is generally considered to be an early sign of primordial follicle activation (Gougeon \& Busso 2000). However, it cannot be excluded that the presence of more intermediate and primary follicles could be the result of an experimental artifact, such as the swelling of granulosa cells. Swelling of granulosa cells has indeed been 
reported in follicles after culture and also after grafting (Gosden et al. 2002, Smitz \& Cortvrindt 2002). Nevertheless, follicular activation, as suggested by the presence of Ki-67-positive granulosa cells in grafted follicles, may certainly be hypothesized.

In vitro too, the vast majority of primordial follicles in ovarian cortical pieces from rodents, cattle, baboons, and adult women activate spontaneously after as little as $24 \mathrm{~h}$ culture (Wandji et al. 1997, Hovatta et al. 1999, Fortune 2003, Skinner 2005). Culture of human adult ovarian cortical slices for 7 days resulted in a $37 \%$ increase in the number of primary follicles and a $6 \%$ increase in secondary follicles (Carlsson et al. 2006), which is in the same range as observed after in vivo transplantation in the present study. This premature granulosa cell activation may lead to uncoordinated growth of granulosa cells and oocytes, as suggested in vitro by Smitz \& Cortvrindt (2002). This is supported by our recent observation by TEM that, 3 weeks after grafting human ovarian fragments into nude mice, most secondary follicles showed asynchrony between granulosa cell maturation and oocyte maturation (Camboni et al. 2005).

Little is known about the factors controlling the primordial to primary follicle transition in humans. Mechanisms regulating activation are likely to be under the coordinated control of both stimulatory and inhibitory signals (Gougeon \& Busso 2000). It has been suggested that anti-Müllerian hormone $(\mathrm{AMH})$ produced by developing follicles inhibits the recruitment of primordial follicles (Baird et al. 2004). AMH has indeed been shown to inhibit follicular activation in mice, bovines, sheep and, recently, humans (Durlinger et al. 2002, Fortune 2003, Gigli et al. 2005, Carlsson et al. 2006). This inhibitory factor is produced by early secondary, preantral and antral follicles in several species (Weenen et al. 2004). However, it remains to be confirmed whether AMH also has an inhibitory effect in humans, since Schmidt et al. (2005) reported that $\mathrm{AMH}$ initiates growth of human primordial follicles in vitro. The absence of antral follicles and the lack of secondary and preantral follicles in grafted cortical fragments and isolated follicle preparations in the present study may have disrupted the balance between stimulatory and inhibitory factors, thereby inducing follicular activation. This massive follicular activation observed shortly after ovarian cortex grafting may lead to an accelerated depletion of the reserve of non-growing follicles (Gougeon \& Busso 2000). Nevertheless, such a follicular loss after grafting does not preclude development up to the antral or ovulatory stage, as recently demonstrated by Gook et al. (2003).

Xenotransplantation of isolated follicles may provide a useful model to study the interaction between follicles and stromal cells. No model is presently available, as isolated human primordial follicles do not grow beyond the secondary stage in culture (Hovatta et al. 1999), and organ culture renders the study of stromal interaction impossible. Another advantage of this model is that it allows control of the graft compositions, since transplantation of isolated follicles involves in vitro isolation of follicles (Gosden 1990).

Isolated follicles survive and grow after xenotransplantation and are able to form an apparently normal cortex. These promising results indicate that this approach warrants further investigation, with a view to potential clinical application as an alternative to cortical fragment transplantation, in patients at risk of ovarian metastasis, for example. As we showed that the developing stroma around the follicles in the graft may well originate from residual human stromal cells after follicle isolation, the follicle isolation procedure should be improved before clinical application. Another possibility is to purge the isolated follicle suspension of malignant cells with specific antibodies, as described by Schröder et al. (2004), which would require specific malignant cell detection systems. If stromal cells are needed for follicular growth, fully isolated follicles from cryopreserved tissue could be grafted together with autologous fresh stromal cells (from a new ovarian biopsy after cancer treatment).

However, before this procedure can be considered for future clinical use, the present protocol needs to be adapted. Replacing FBS with patient serum or human serum albumin is a modification that will need to be made to avoid the use of components of animal origin. The surgical technique will also have to be improved to increase the efficiency of graft recovery, and adapted to the human anatomy, as humans do not have an ovarian bursa. Grafting isolated follicles to subcortical tissue would allow interaction between the graft and the ovarian stroma. It is also essential to keep the time between biopsy collection and follicle grafting to a minimum. Although some studies show that human ovarian tissue can tolerate at least a 4-h delay (Schmidt et al. 2003), others indicate that this delay may have an impact on follicle viability (Cleary et al. 2001, Snow et al. 2001). During our follicle isolation procedure, follicles were picked up with a micropipette under a stereomicroscope, and a method was developed to shorten the time needed for follicle recovery using a Ficoll density gradient to separate isolated follicles from stromal cells (Martinez-Madrid et al. 2004).

In conclusion, we were able to demonstrate follicular survival and the formation of stroma-like tissue of human origin after short-term xenotransplantation of isolated human follicles to nude mice. Xenotransplantation of isolated follicles may provide a useful model to investigate the cross-talk between stromal and follicular cells. This study also highlights the importance of analyzing the initial post-grafting stages, as premature follicular activation could accelerate follicular depletion of the graft. 


\section{Acknowledgements}

The present study was supported by grants from the Fonds National de la Recherche Scientifique de Belgique (grant nos 7.4519.04 and 7.4547.06), the Fondation St Luc, the Belgian Federation Against Cancer (non-profit organization) and donations from $\mathrm{A}$ Frère and $\mathrm{Ph}$ De Spoelberch. We thank the Institute of Statistics of Louvain-La-Neuve (UCL) for their precious help, Dolores Gonzalez for her technical assistance, Dr Aude Coupé for the set up of the animal model, Prof. Marbaix from the Department of Pathology for his invaluable advice, and Mira Hryniuk and Anne Lepage for their corrections. The authors declare that there is no conflict of interest that would prejudice the impartiality of this scientific work.

\section{References}

Abir R, Fisch B, Nitke S, Okon E, Raz A \& Ben Rafael Z 2001 Morphological study of fully and partially isolated early human follicles. Fertility and Sterility 75 141-146.

Antczak M \& Van Blerkom J 2000 The vascular character of ovarian follicular granulosa cells: phenotypic and functional evidence for an endothelial-like cell population. Human Reproduction $\mathbf{1 5}$ 2306-2318.

Baird D T, Campbell B, de Souza C \& Telfer E 2004 Long-term ovarian function in sheep after ovariectomy and autotransplantation of cryopreserved cortical strips. European Journal of Obstetrics, Gynecology and Reproductive Biology 113 S55-S59.

Bristol S \& Woodruff T 2004 Follicle-restricted compartmentalization of transforming growth factor $\beta$ superfamily ligands in the feline ovary. Biology of Reproduction 70 846-859.

Camboni A, Martinez-Madrid B, Dolmans MM, Macchiarelli G, Donnez J \& Nottola SA 2005 Contribution of transmission electron microscopy to the study of human ovarian tissue integrity after enzymatic isolation, cryopreservation or xenografting. Fertility and Sterility 84 S104.

Carlsson IB, Laitinen MP, Scott JE, Louhio H, Velentzis L, Tuuri T, Aaltonen J, Ritvos O, Winston RM \& Hovatta O 2006 Kit ligand and c-Kit are expressed during early human ovarian follicular development and their interaction is required for the survival of follicles in long-term culture. Reproduction 131 641-649.

Carroll J \& Gosden RG 1993 Transplantation of frozen-thawed mouse primordial follicles. Human Reproduction 8 1163-1167.

Cleary M, Snow M, Paris M, Shaw J, Cox SL \& Jenkin G 2001 Cryopreservation of mouse ovarian tissue following prolonged exposure to an Ischemic environment. Cryobiology 42 121-133.

Czernobilsky B, Moll R, Levy R \& Franke WW 1985 Co-expression of cytokeratin and vimentin filaments in mesothelial, granulosa and rete ovarii cells of the human ovary. European Journal of Cell Biology 37 175-190.

Demeestere I, Simon P, Buxant F, Robin V, Fernandez Aguilar S, Centner J, Delbaere A \& Englert Y 2006 Ovarian function and spontaneous pregnancy after combined heterotopic and orthotopic cryopreserved ovarian tissue transplantation in a patient previously treated with bone marrow transplantation: Case Report. Human Reproduction 21 2010-2014.

Dolmans MM, Michaux N, Camboni A, Martinez-Madrid B, Van Langendonckt A, Nottola S \& Donnez J 2006 Evaluation of Liberase, a purified enzyme blend, for the isolation of human primordial and primary ovarian follicles. Human Reproduction 21 413-420.

Donnez J, Dolmans MM, Demylle D, Jadoul P, Pirard C, Squifflet J, Martinez-Madrid B \& Van Langendonckt A 2004 Livebirth after orthotopic transplantation of cryopreserved ovarian tissue. Lancet 364 1405-1410.
Donnez J, Martinez-Madrid B, Jadoul P, Van Langendonckt A, Demylle D \& Dolmans MM 2006 Ovarian tissue cryopreservation and transplantation: a review. Human Reproduction Update 12 519-535.

Durlinger AL, Gruijters MJ, Kramer P, Karels B, Ingraham HA, Nachtigal MW, Uilenbroek JT, Grootegoed JA \& Themmen AP 2002 Anti-Mullerian hormone inhibits initiation of primordial follicle growth in the mouse ovary. Endocrinology 143 1076-1084.

Eppig JJ 1994 Further reflections on culture systems for the growth of oocytes in vitro. Human Reproduction 9 974-976.

Fortune JE 2003 The early stages of follicular development: activation of primordial follicles and growth of preantral follicles. Animal Reproduction Science 78 135-163.

Gigli I, Cushman RA, Wahl CM \& Fortune JE 2005 Evidence for a role for anti-müllerian hormone in the suppression of follicle activation in mouse ovaries and bovine ovarian cortex grafted beneath the chick chorioallantoic membrane. Molecular Reproduction and Development 71 480-488.

Gook DA, Edgar DH, Borg J, Archer J, Lutjen PJ \& McBain JC 2003 Oocyte maturation, follicle rupture and luteinization in human cryopreserved ovarian tissue following xenografting. Human Reproduction 18 1772-1781.

Gosden RG 1990 Restitution of fertility in sterilized mice by transferring primordial ovarian follicles. Human Reproduction 5 499-504.

Gosden RG, Mullan J, Picton HM, Yin H \& Tan SL 2002 Current perspective on primordial follicle cryopreservation and culture for reproductive medicine. Human Reproduction Update 8 105-110.

Gougeon A 1996 Regulation of ovarian follicular development in primates: facts and hypotheses. Endocrine Reviews 17 121-155.

Gougeon A \& Busso D 2000 Morphologic and functional determinants of primordial and primary follicles in the monkey ovary. Molecular and Cellular Endocrinology 163 33-41.

Hovatta O, Wright C, Krausz T, Hardy K \& Winston RML 1999 Human primordial, primary and secondary ovarian follicles in long-term culture: effect of partial isolation. Human Reproduction $\mathbf{1 4}$ 2519-2524.

Huntriss J, Gosden R, Hinkins M, Oliver B, Miller D, Rutherford AJ \& Picton HM 2002 Isolation, characterization and expression of the human factor in the germline alpha (FIGLA) gene in ovarian follicles and oocytes. Molecular Human Reproduction 8 1087-1095.

Lass A, Silye R, Abrams DC, Krausz T, Hovatta O, Margara R \& Winston RM 1997 Follicular density in ovarian biopsy of infertile women: a novel method to assess ovarian reserve. Human Reproduction 12 1028-1031.

Martinez-Madrid B, Dolmans MM, Van Langendonckt A, Defrère S, Van Eyck AS \& Donnez J 2004 Ficoll density gradient for recovery of isolated human ovarian primordial follicles. Fertility and Sterility $\mathbf{8 2}$ 1648-1653.

Meirow D, Levron J, Eldar-Geva T, Hardan I, Fridman E, Zalel Y, Schiff E \& Dor J 2005 Pregnancy after transplantation of cryopreserved ovarian tissue in a patient with ovarian failure after chemotherapy. New England Journal of Medicine 353 318-321.

Nisolle M, Casanas-Roux F, Qu J, Motta P \& Donnez J 2000 Histological and ultrastructural evaluation of fresh and frozenthawed human ovarian xenografts in nude mice. Fertility and Sterility 74 122-129.

Oktay K, Nugent D, Newton H, Salha O, Chatterjee P \& Gosden RG 1997 Isolation and characterization of primordial follicles from fresh and cryopreserved human ovarian tissue. Fertility and Sterility $\mathbf{6 7}$ 481-486.

Oktay K, Newton H \& Gosden RG 2000 Transplantation of cryopreserved human ovarian tissue results in follicle growth initiation in SCID mice. Fertility and Sterility 73 599-603.

Schmidt KL, Ernst E, Byskov AG, Nyboe Andersen A \& Yding Andersen C 2003 Survival of primordial follicles following prolonged transportation of ovarian tissue prior to cryopreservation. Human Reproduction 18 2654-2659. 
Schmidt KL, Kryger-Baggesen N, Byskov AG \& Yding Andersen C 2005 Anti-Müllerian hormone initiates growth of human primordial follicles in vitro. Molecular and Cellular Endocrinology 234 87-93.

Schröder CP, Timmer-Bosscha H, Wijchman JG, de Leij LF, Hollema H, Heineman MJ \& de Vries EG 2004 An in vitro model for purging of tumour cells from ovarian tissue. Human Reproduction 19 1069-1075.

Skinner MK 2005 Regulation of primordial follicle assembly and development. Human Reproduction Update 11 461-471.

Smitz JE \& Cortvrindt RG 2002 The earliest stages of folliculogenesis in vitro. Reproduction 123 185-202.

Snow M, Cleary M, Cox SL, Shaw J, Paris M \& Jenkin G 2001 Comparison of the effects of in vitro and in situ storage on the viability of mouse ovarian tissue collected after death. Reproduction, Fertility and Development 13 389-394.
Wandji SA, Srsen V, Nathanielsz PW, Eppig JJ \& Fortune JE 1997 Initiation of growth of baboon primordial follicles in vitro. Human Reproduction 12 1993-2001.

Weenen C, Laven JS, Von Bergh AR, Cranfield M, Groome NP, Visser JA, Kramer P, Fauser BC \& Themmen AP 2004 Anti-Müllerian hormone expression pattern in the human ovary: potential implications for initial and cyclic follicle recruitment. Molecular Human Reproduction 10 77-83.

Received 20 March 2007

First decision 29 March 2007

Accepted 4 May 2007 